\title{
Quantifiers and propositional attitudes: Quine revisited
}

\author{
Sean Crawford
}

Received: 23 April 2005 / Accepted: 24 July 2006 / Published online: 15 February 2007

(C) Springer Science+Business Media B.V. 2006

\begin{abstract}
Quine introduced a famous distinction between the 'notional' sense and the 'relational' sense of certain attitude verbs. The distinction is both intuitive and sound but is often conflated with another distinction Quine draws between 'dyadic' and 'triadic' (or higher degree) attitudes. I argue that this conflation is largely responsible for the mistaken view that Quine's account of attitudes is undermined by the problem of the 'exportation' of singular terms within attitude contexts. Quine's system is also supposed to suffer from the problem of 'suspended judgement with continued belief'. I argue that this criticism fails to take account of a crucial presupposition of Quine's about the connection between thought and language. The aim of the paper is to defend the spirit of Quine's account of attitudes by offering solutions to these two problems.
\end{abstract}

Keywords Belief contexts - Belief de dicto $\cdot$ Belief de re . Dyadic belief - Exportation · Kaplan · National belief · Propositional attitudes · Quantifying in · Quine · Relational belief $\cdot$ Suspension of judgement . Triadic belief

\section{Introduction}

It has been 50 years since the publication of Quine's seminal article 'Quantifiers and Propositional Attitudes' (Q\&PA), in which he introduced a now famous, but still widely misunderstood, distinction between the notional sense and the relational sense of certain psychological verbs, such as 'hunting', 'wishing', 'wanting' and 'believing'. \footnotetext{
(Quine, 1977).

S. Crawford $(\varangle)$ Institute for Philosophy and Public Policy, Lancaster University, Lancaster LA1 4YG, UK e-mail: s.crawford@lancaster.ac.uk
}

1 See also chapters four and five of Word and Object (Quine, 1960) and 'Intensions Revisited' 
In that same paper, Quine also introduced another distinction between dyadic and triadic (or higher degree) cases of what he later, in 'Intensions Revisited', took to be the multigrade predicates 'hunting', 'wishing', 'wanting' and 'believing'. Many commentators seem to take the distinctions to be at bottom the same, in the sense that they appear to think that the latter is a logical formalization of the former. I shall argue that this is incorrect, that the distinctions are not the same, and that, moreover, once they are clearly separated, and a minor modification is made to Quine's system, a clear and simple solution to the problem of the 'exportation' of singular terms within attitude contexts presents itself. The second and closely related issue I will discuss is an assumption Quine makes about the connection between language and thought, an assumption that plays a crucial role in his conception of belief. I will argue that once this assumption is made explicit, a clear solution emerges to another problem that allegedly undermines Quine's account of attitudes. This is the problem of 'suspended judgement with continued belief'. The purpose of this paper is, then, to defend Quine's account of attitudes by offering solutions to these two problems.

\section{Relational versus notional states of mind}

The overall theme of Q\&PA is how to symbolize two readings of ambiguous natural language sentences containing psychological verbs - such as 'I want a sloop' and 'Ralph believes that someone is a spy'- using an extensional and first-order logic in which the quantifiers receive their standard objectual interpretation. The latter sentence, for example, could mean either 'Ralph believes there are spies' or 'Someone is believed by Ralph to be a spy' and the former either 'I want relief from slooplessness', as Quine humorously puts it, or 'There is a particular sloop I want'. Quine calls the former readings 'notional' and the latter 'relational'. The first thing to notice here is that these two readings are each reports of two different kinds of states of mind. The relational states of mind are such that, if the foregoing attitude reports are true, then there is someone to whom is Ralph belief-related, via the token relational state of mind in question, and some sloop to which I am desire-related, via the token relational state of mind in question (though, crucially, to anticipate, neither Ralph nor I may know precisely which objects our respective token mental states relate us to-more on this in Sect. 8 below). The notional states of mind, on the other hand, are such that, if the corresponding attitude reports are true, then it is not the case that there is something to which the subjects are related in virtue of being in those token states of mind. As some philosophers have pointed out (Forbes, 2000; Richard, 2001), the notional reading is often brought out in ordinary parlance by adding a 'but no particular one' rider to the original ambiguous ascription: for example, 'I want a sloop, but no particular one', 'Ralph believes that someone is a spy, but not that anyone in particular is'. As Quine's terms aptly suggest, relational senses of attitude verbs assert a relation between the holder of the attitude and a particular object, whereas notional senses imply that no such relation holds. Forbes has recently expressed the idea as one of 'domain independence': 'The core of notionality is the idea of not standing in the relation to an element of the domain' (2000, p. 146). To this we can add, the core of relationality is the idea of standing in the relation 
to an element of the domain - 'domain-dependence', for short. ${ }^{2}$ Quine's question is then: Does elementary logic contain the resources for representing these two kinds of states mind? ${ }^{3}$

\section{The problem of quantifying in}

Prima facie, it seems as if the matter can be resolved à la Russell simply by attending to the scope of quantifiers. Thus, the vernacular ambiguity of 'Ralph believes that someone is a spy' is treated as a syntactical ambiguity between readings that differ in the permutations of their quantifiers and psychological verbs:

(1) Ralph believes that $(\exists x)$ ( $x$ is a spy).

(2) $(\exists x)$ (Ralph believes that $x$ is a spy).

But, Quine notes, the formalization of the relational sense (2) involves 'quantifying into a propositional attitude idiom from outside', and this, he claims, 'is a dubious

2 As Forbes (2000) and Richard (2001) both point out, it is not only indefinite noun phrases, such as 'a spy', occurring in complement clauses, that induce the notional/relational ambiguity in attitude sentences. Forbes offers the following examples as further types: 'Perseus seeks three gorgons' and 'Perseus seeks every gorgon' and goes so far as to claim that 'All [quantified noun phrases] generate the ambiguity' (p. 165). Richard's very similar examples include: 'Mary expects 17 football players' and 'Mary sought every survivor of the plane crash'. Although both philosophers are concerned exclusively with objectual attitudes (see note 20), it would appear that the same is true of at least some propositional attitudes; e.g. the sentences 'Ralph believes that ten FBI agents are spies' and 'Ralph believes that every FBI agent is a spy'. Exactly which kinds of subject terms in complement clauses generate the relational/notional ambiguity is a difficult question. Interestingly, subject terms that are definite descriptions, e.g., do not appear in any of Forbes's or Richard's explicit examples (though admittedly Forbes at one point, on p. 178, seems to suggest-mistakenly, in my view-that definite descriptions occurring as subject terms in complement clauses can generate notional readings). But do they too exhibit the notional/relational ambiguity? More to the point, can definite descriptions be used as subject terms in complement clauses to report notional states? Consider an ascription such as 'Ralph is looking for the exit', uttered in a context in which Ralph is searching for what he justifiably believes to be the only exit to an underground parking lot he has never been in before. Can this sentence be used to report a notional state? It seems to me that it cannot and that it perforce reports a relational state. For by intending to find the exit, Ralph puts himself in the looking for relation to an element in the domain, namely, the exit in question. Moreover, pace Forbes (2000, p. 178), it does not seem to make any sense to say 'Ralph is looking for the exit, but no exit in particular'. On the contrary, he is looking for a particular exit, namely, the exit to the parking lot in which he finds himself. What is certainly true is that Ralph is looking for the exit, wherever that is exactly (or perhaps, whichever part of the parking lot that is exactly). But a 'whichever/whoever that is' rider is not the same as a 'but no particular one' rider. The latter rules out the possibility of a relational reading whereas the former merely declares, among other things, that there is a sense in which the subject of the relational ascription does not know which element in the domain he is related to. As I shall argue in Sect. 8, it is absolutely crucial to distinguish between being related to an element in the domain, on the one hand, and, on the other, knowing (in some salient sense) which element in the domain it is that one is related to. The issue here is of course complicated by the fact that a Russellian analysis of definite descriptions treats them as purely 'general' and thus, in a sense, not really 'about' any particular item (they do not refer but merely 'denote' and so are not genuine singular terms; moreover, their meanings are 'object-independent'). For an excellent discussion of this issue and how it relates to Quine see Dennett (1982, pp. 191ff). I am grateful to an anonymous referee for this journal for comments that prompted this note and also for the example of the parking lot exit.

3 In what follows I will be concerned solely with relational attitudes directed towards contingently existing spatio-temporal particulars. So I will not discuss relational attitudes about universals (such as colours) or necessarily existing abstract objects (such as numbers). For some discussion of relational attitudes to universals see Dennett (1982, pp. 176ff). 
business, as may be seen from the following example' (p. 185). The example is, of course, the famous story of Ralph who has seen a suspicious character in a brown hat who he thinks is a spy. Ralph has also seen a grey haired man at the beach who he thinks is a pillar of the community and who is known to him as 'Bernard J. Ortcutt'. Unbeknownst to Ralph, Ortcutt is both pillar and spy. Given this identity, Quine then asks whether we can say of this man, Bernard J. Ortcutt, that Ralph believes him to be a spy. If we answer affirmatively, Quine says, then we must accept conjunctions of the following type:

(LTD) $w$ sincerely denies '...' and believes that ...

in which the blanks are filled by the same sentence ('LTD' for 'Language-Thought Disparity'; in Q\&PA this is simply numbered (11)). This is because Ralph denies that the sentence 'Ortcutt is a spy' is true. But LTD-type conjunctions are apparently unacceptable, thinks Quine (though, it must be said, he gives no reason whatsoever for maintaining this). Following this line of thought, that LTD-type conjunctions are to be barred, we end up countenancing the truth of the following:

(3) Ralph believes that the man in the brown hat is a spy

(4) Ralph does not believe that the man seen at the beach is a spy

and thus acquiescing in the referential opacity of the context 'believes that ...'. The context is referentially opaque because the singular term position is not purely referential, that is, does not function simply to introduce an object for predication. Quine takes substitution of coreferential singular terms salva veritate as the criterion for whether a term position is purely referential (1960, p. 142). ${ }^{4}$ Referentially transparent contexts are ones in which all singular term positions are purely referential. Quine assumes that (3) and (4) describe a relation between Ralph and Ortcutt only if the term positions in the complement clauses (the ones occupied by 'the man in the brown hat' and 'the man seen at the beach') are purely referential. Since they are not purely referential, because substitution salva veritate fails, he concludes that (3) and (4) 'cease to affirm any relationship between Ralph and any man at all' (p. 185). It follows from this that 'It then becomes improper to quantify as in (2)' (pp. 185-186). Since substitution and quantification go hand-in-hand, 'Yet we are scarcely prepared to sacrifice the relational constructions' (p. 186), we are stuck with the problem of how to render formally the 'indispensable' relational readings. ${ }^{5}$

4 Quine's criterion for referential opacity appears to shift between failure of referential transparency and the illegitimacy of quantifying in. See Kaplan (1986) and Quine (1986a) for discussion of the matter. I follow Forbes (1996) and take Quine as arguing from the failure of substitutivity in attitude ascriptions to the illegitimacy of quantifying into them.

5 The move from the failure of substitution to the non-affirmation of any relationship between Ralph and any man appears to be a non-sequitur. Failure of substitution into a singular term position does not seem to indicate that the containing sentence ceases to affirm a relationship between person and object (e.g., between Ralph and Ortcutt). A number of philosophers, such as Loar (1972), have pointed out that singular term positions within psychological contexts certainly seem to be able to relate the thinker to an object while resisting substitution. So perhaps Quine's well-known thesis that 'a position that resists substitutivity of identity cannot meaningfully be quantified' (Quine, 1986a, p. 291), as applied to attitude ascriptions, cannot be defended on the grounds that a substitution-resistant position within a sentence indicates that that sentence does not affirm a relationship between a person and an object. Nevertheless, as Forbes (1996) has shown, a more cautious and restricted version of the thesis, applied only to attitude ascriptions, can be defended on other grounds. The larger issue of whether Quine's general thesis is true is discussed at length by Kaplan (1986) and Fine $(1989,1990)$; see also Quine's (1986a) reply to Kaplan. 
It is evident that Quine's argument here hinges crucially on the rarely noticed premise that LTD-type conjunctions must be disallowed (discussed in detail in Sect. 9 below).

\section{Quine's intensionalist solution}

Quine's solution to the problem essentially involves providing logical forms for attitude ascriptions in which the singular term in the complement clause is moved outside the substitution-resistant position and into a purely referential position where it is thus open to both substitution and quantification. ${ }^{6}$ Kaplan describes Quine's resolution of the puzzle as one that rejects Russell's analysis in terms of syntactical ambiguity and concluding that there is a lexical ambiguity in the propositional verbs themselves (1986, p. 132). Quine's proposal is regularly described as one that posits a semantical ambiguity where Russell proposed a syntactical one. ${ }^{7}$ According to this interpretation, there is a sense of 'wishing' and 'believing' that permits both substitution and quantification and a sense that permits neither and 'The two senses differ in logical syntax and cannot be transformed into one another by moving quantifiers around' (loc. cit.). This is certainly the standard interpretation of Quine's distinction. But it is absolutely crucial to note that no sooner has Quine suggested that we resolve the problem of quantifying in by positing two different senses of 'belief' - in his words, 'belief ${ }_{1}$, which disallows [LTD], and belief 2 , which tolerates [LTD] and makes sense of (2)' - than he rejects the idea, offering instead a 'more suggestive treatment' (1956, p. 186). This more suggestive treatment is one that operates with a single sense of 'belief', belief 1 , according to which LTD-type conjunctions are 'disallowed'.

It is important not to confuse the two senses of 'belief' posited by the proposal that Quine rejects, which is sustained for all of one small paragraph, with the notional and the relational senses of 'belief' that form the subject matter of Q\&PA. The problem that symbolizing notional and relational readings of belief ascriptions gives rise to - namely, the need to quantify in, yet the apparent incoherence of doing so - is the motivation for positing belief ${ }_{1}$ and belief 2 , but the two pairs of 'senses' of 'belief' are not the same. The former is a pre-theoretical commonsense distinction while the latter is a theoretical proposal about how to deal with the technical problem of 'quantifying in' generated by the desire to symbolize logically the commonsense distinction.

The proposal Quine goes on to advocate, instead of the belief /belief $_{2}$ approach, is one that treats the psychological verbs as multigrade predicates, not only capable of taking a arbitrary number of arguments - like '.. are parallel', ' $\ldots$ are colleagues', '.. live together' - but also capable of taking arguments of different kinds, namely, believers, particular objects, and 'intensions' (i.e., properties, relations, and propositions). ${ }^{8}$ 'Believes' always takes a subject and an intension as arguments and it is the names of the intensions only that are always referentially opaque. The single predicate 'belief'

6 This is the essence of Forbes's (1996) account as well as those of Loar (1972) and Burge (1977a).

7 E.g., Richard (1990, p. 129) and Stich, (1983, p. 112). Cf. Stalnaker who, even more oddly, claims that Quine explains relational belief in terms of notional (1998, p. 160). As John Wallace (1972) pointed out long ago, and Kripke very recently (2005, p. 1010n11), Quine does precisely the reverse, by analogy with the relation between truth and satisfaction.

8 See also Quine, 1960, Sect. 35 and 1977. To my knowledge, the proposal is first called 'multigrade' by Quine in 'Intentions Revisited' (1977, p. 268); though he there suggests that the 1956 proposal in Q\&PA was a multigrade one. The idea is in effect a reworking of Russell's (1910) 'multiple relation theory of judgement', with the addition of propositions as possible relata (precisely that which Russell sought to avoid). To my knowledge Quine nowhere links his proposal to Russell's. Given Quine's 
(the original 'belief $f_{1}$ ') is then taken as having dyadic, triadic, tetradic and higher degree cases. Dyadic belief relates the believer to a proposition - for example, 'Ralph believes that Ortcutt is a spy' (which, given the story, is false). The triadic, tetradic and higher degrees relate a believer to a property or relation and an object, where the singular term referring to the object is in referential position and so open to substitution and quantification. So, for example, using Quine's later notation for intensional abstraction (1960, Sects. 34 and 35), 'Ralph believes Ortcutt to be a spy', can be represented as:

(6) Believes (Ralph, $x[x$ is a spy], Ortcutt),

in which ' $x[x$ is a spy]' names the property (or 'attribute', as Quine would say) of spyhood. The incoherent (2) is replaced with the coherent:

(7) $\exists y($ Believes (Ralph, $x[x$ is a spy $], y)$ ),

which involves no 'illicit' quantification into an opaque context. The false 'Ralph believes that Ortcutt is a spy' comes out as:

(8) Believes (Ralph, [Ortcutt is a spy]),

where '[Ortcutt is a spy]' designates a proposition. The true (1) comes out as:

(9) Believes (Ralph, $[(\exists x)$ ( $x$ is a spy)]),

which involves only 'licit' quantification within an opaque context. Quine sums up his technical solution to the problem of providing 'for those indispensable relational statements of belief' (1956, p. 189) thus: 'the notation of intensions, of degree one and higher, is in effect a device for inking a boundary between referential and non-referential occurrences of terms' (ibid.). Relational readings of attitude ascriptions are thus made consistent with the ban on quantifying into non-referential position. ${ }^{9}$

Terminology in this area can be extremely confusing. The notional/relational, dyadic/triadic and belief $_{1} /$ belief $_{2}$ contrasts are intertwined with several other pairs of terms, most notably de dicto/de re. For Quine, it seems that de dicto belief is simply dyadic belief and de re belief is triadic or tetradic or any higher degree belief (see Quine 1977). Henceforth, I shall use 'de re belief' when referring to triadic and higher degree belief and 'de dicto belief' when referring to dyadic belief, though I shall sometimes revert to the latter terms. 'De re belief' has the added advantage of covering triadic and all higher degree beliefs and thus can replace the tedious phrase 'triadic and higher degree belief'. 10

Footnote 8 continued

close familiarity with Russell's philosophy this is perhaps a little surprising. Indeed, as Kripke (2005, p. 1010) observes, Quine's example of the sloop is also reminiscent of Russell's earlier well-known example of the yacht in 'On Denoting'.

9 As is well known, Quine, of course, does not rest content with an analysis that appeals to intensions, which he famously views as 'creatures of darkness'. He goes on to pursues his strategy of 'semantic ascent' by replacing the intensional entities, attributes and propositions, with extensional ones, predicates and sentences named by quotation marks. I am interested in defending what seems to me the more plausible intensionalist account or, more accurately, a modified version of it (presented in Sect. 7 below). So in what follows I shall stick with intensions, speaking freely of properties and propositions even when discussing Quine's views, while noting here that Quine himself officially abjures such notions. For criticism of Quine's sententialist theory of belief see Salmon (1995).

10 In Word and Object, Quine speaks provisionally of 'opaque' and 'transparent' belief (1960, Sects. 30 and 31), meaning 'believes that ...' contexts that are, respectively, referentially opaque and referentially transparent, in other words, Q\&PA's belief ${ }_{1}$ and belief 2 . Again, however, this idea is mooted only to be rejected.

Springer 
The important point for present purposes, however, is that the relational/notional and de re/de dicto (i.e., triadic and higher degree/dyadic) distinctions do not map neatly onto one another and Quine, so far as I am aware, never actually says that they do. Many of his commentators nevertheless seem to assume that they are intended to be the same distinction. ${ }^{11}$ In an earlier paper, Forbes (1996, p. 347), for example, says that:

Quine would say that ['Lois Lane doubts that Clark Kent can help her'] contains a potential ambiguity between notional and relational senses of 'doubts'. The notional sense is the dyadic 'doubts ${ }^{2}$ ' and the relational ones are of higher degree, for example an 'irreducibly triadic' 'doubts ${ }^{3}$. ${ }^{12}$

But as the complement clause of the attitude ascription in question makes reference to a particular person (Clark Kent), Lois's state of mind cannot be notional. There is no room for a relational/notional ambiguity here, as there might be with the quantified ascription 'Lois Lane doubts that someone can help her'. Forbes is perfectly correct, of course, that there seems to be room for a potential ambiguity turning on the question whether the position occupied by 'Clark Kent' permits substitution, and which is resolvable in terms of de dicto (dyadic) and de re (triadic) belief. ${ }^{13}$ (Reverting to the rejected distinction, Quine would perhaps say that there is a belief $1 /$ belief $_{2}$ ambiguity here, or an opaque belief/transparent belief ambiguity, in the language of Word and Object (1960, Sects. 30 and 33), as these contrasts are defined in terms of substitution failure.) So, it appears that for all Quine has said, there are cases of relational de dicto belief. On the face of it, Forbes's example is precisely an example of a relational de dicto (i.e., dyadic) belief. This raises a serious problem for Quine and I think that this problem is connected to the reason why there is a tendency to conflate the notional/relational and de dicto/de re (dyadic/triadic) distinctions.

11 E.g., Wallace (1972), Burge (1977b), Dennett (1982), Salmon (1995), Forbes (1996) and Recanati (2000).

12 François Recanati claims that Quine's view is that 'belief sentences in general are ambiguous between the relational and the notional reading' (2000, p. 255) and says that '[Quine] thinks that a standard belief sentence like "Ralph believes that Ortcutt is a spy" is ambiguous between the relational and the notional reading' (p. 257). But even the most cursory glance at Q\&PA confirms that Quine thinks no such thing. The relational/notional contrast is explicitly introduced by him with reference to attitude ascriptions whose complement clauses contain quantified noun phrases ('Ralph believes that someone is a spy'). The only remark Quine passes on the ascription 'Ralph believes that Ortcutt is a spy' is that it is 'a dyadic relation of belief between a believer and a proposition' (p. 186). Some of the confusion here may be owing to the fact that in his later 1977 paper 'Intensions Revisited', as well as all subsequent writings that I am aware of, Quine drops all discussion of the relational/notional contrast and, perhaps under the influence of Kaplan, turns his attention to de re and de dicto belief reports (similarly, the relational/notional contrast makes no appearance in Word and Object, though there is much on 'transparent' and 'opaque' belief). Even so, pace Dennett (1982, p. 175), there is no indication that Quine intends the later terminology merely to replace the earlier. At any rate, we shall see presently that the sentence 'Ralph believes that Ortcutt is a spy' can only be interpreted as the attribution of a relational state of mind to Ralph and that this is a serious problem for Quine's view.

13 I should add that in Forbes's later paper, which is squarely focused on the relational/notional contrast in a way that the earlier one was not, he acknowledges this error, rightly pointing out that 'The problems of representing notional readings and of explaining resistance to substitutivity are independent (2000, p. 165; see also the entire first section, especially p. 145, n11, where he explicitly criticizes his earlier 1996 paper on this point). I am again grateful to an anonymous referee for directing me to this excellent article by Forbes. 


\section{Quine's (real) problem with exportation}

Quine never says whether the de dicto

(8) Believes (Ralph, [Ortcutt is a spy])

should be taken as relational. This is no doubt because he is primarily interested in the logical problems raised by quantified attitude ascriptions. Nevertheless, intuitively, (8) reports a relational state of mind; it appears, at any rate, to say something not only about Ralph but about Ortcutt as well. But this is flatly inconsistent with Quine's proposal that '[Ortcutt is a spy]' is referentially opaque and that Ortcutt 'does not receive reference' in (8). As many philosophers have pointed out, this part of Quine's proposal is extremely implausible. After all, Ralph's belief here is true if and only if the man B. J. Ortcutt is a spy; his belief thus concerns Ortcutt in the very clear sense that the belief's truth value depends on the condition of Ortcutt (Loar, 1972; Dennett, 1982; Forbes, 1996). But how can Ralph's belief concern Ortcutt in this sense and at the same time, (8) 'not ... [be] ... about Ortcutt at all' (1956, p. 185)? Things become even more puzzling with Quine's view that there is a connection between de dicto belief and de re belief, embodied in his claim that a certain kind of inference, which he calls 'exportation', is generally valid, namely:

$\beta$ believes $[\Phi \alpha]$

$\exists \gamma(\gamma=\alpha)$

Therefore, $\beta$ believes $\alpha$ to be $\lambda\left[\Phi_{\lambda}\right]$.

This means that from the dyadic or de dicto (8), and the fact that Ortcutt exists, we can infer the triadic or de re (6). That is, from the fact that Ralph believes that Ortcutt is a spy, together with Ortcutt's existence, we can infer that Ortcutt is believed by Ralph to be a spy. ${ }^{14}$ But, as Loar (1972) has pointed out, if (6) is relational, surely (8) must be too; otherwise it is hard to see how exportation could be valid. But, though (8) is the report of a relational state of mind, Quine's view that its square brackets, and similarly the two occurrences of 'that' in (3) and (4), must all be taken as 'sealing off' the sentential complements, and thus not 'about Ortcutt at all', prevents it from being taken relationally. Although it has not been generally recognized, this is the real problem about exportation that Quine faces. Luckily for Quine, the problem can be solved.

\section{The conflation of notional belief with de dicto belief}

Quine's view that the name of the intension in the second of the two argument places of de dicto belief is hermetically sealed off, and thus that any putative designators contained therein carry no reference to any items in the world, is one source, I think, of the common conflation of de dicto belief with notional belief. This mistake is not a trivial terminological one; it has substantive consequences. For it gives rise to the view

14 Whether the second existence premise for exportation is strictly required may depend on whether, and if so, how exactly, the notional/relational contrast can be drawn with respect to attitudes about fictional or mythical entities. Another more pressing concern is whether the elaborated Quinean account of belief de re presented in Sect. 7 below can handle cases involving negative existentials. These are some of the many related issues the discussion of which I shall have to defer to another occasion. 
that there is another, different and much more difficult, problem about exportation that appears insoluble. But when de dicto belief is clearly separated from notional belief the problem vanishes, or at least so I shall argue.

Quine's opacity doctrine for de dicto belief is very implausible. But his claim that notional, that is, domain-independent, belief involves no singular reference is highly plausible, indeed correct. I suggest that the correct idea that notional belief involves no singular reference was inadvertently transferred to de dicto belief, because readers mistakenly thought the de dicto/de re distinction was Quine's technical proposal for symbolizing the notional/relational distinction, and thus the implausibility of Quine's opacity doctrine was disguised. A second major source of confusion stems, I suspect, from the fact that after Kaplan's highly influential commentary on Q\&PA, 'notional' came to be associated, not with 'domain independence', but with 'representational'. It is true that, somewhat oddly, the term 'notional' does not occur anywhere in Kaplan's commentary; nevertheless, Kaplan's paper appears to have directed attention way from the notional/relational contrast and onto the supposedly representational nature of relational belief. This shift in meaning is encouraged by the fact that 'notion' undoubtedly has as one of its meanings 'idea' or 'concept' or 'representation'. So it is very natural to use the term 'notional' for a belief whose content somehow contains the believer's 'idea' or 'representation' of the object of his belief. This is how Crimmins (1995), for example, uses the term: for him 'notions' are simply mental representations. ${ }^{15}$ But 'notion', or more accurately, 'notional', can also mean an inclination to engage in a certain type of activity or a desire for something, as in 'I went to Africa with the notion of shooting a lion' or 'I have a notion to learn how to sail a sloop'. When it is used in this sense, there need be no representation or concept carrying any singular reference to any specific item (though, of course, there may). It is clearly this sense that Quine has in mind when he speaks of the notional senses of attitude verbs. The relational sense is properly taken as contrasting with the notional sense so understood; this is the distinction that sets the agenda for Q\&PA. As I said at the outset, the contrast is between those states of mind that place subjects in relations to particular objects in the domain and those that do not and Quine's original problem is how to symbolize this epistemic distinction. But the multifarious meanings of 'notion' and its cognates, Kaplan's seminal discussion of representation in 'Quantifying In', and the fusing of 'notional/relational' with 'de dicto/de re', led to a subtle - and, I shall argue, illegitimate - shift in what the problem was perceived to be.

Once 'notional' takes on the meaning of 'representational' then the problem becomes one of distinguishing between different kinds of relational states of mind rather than one of distinguishing between relational and notional states of mind. In particular, the problem becomes one of distinguishing between, roughly speaking, thoughts that are somehow very intimately or 'strongly' about their specific objects (the kind Kaplan investigated in Sect. IX of 'Quantifying In') and those that are not very intimately or are only 'weakly' about their specific objects, sometimes also called the 'denotational' (Dennett, 1982) or 'latitudinarian' (Chisholm, 1981) sense of 'aboutness' (cf. Sosa, 1970). The idea is that we can only move from an ascription of de dicto belief to an ascription of de re belief (via exportation) when the content of the de dicto belief in question contains some kind of suitable 'notion' or 'representation'

15 From the Quinean point of view, the very title of his paper, 'Notional Specificity,' is close to oxymoronic. 
of the object of belief that the agent deploys in his thinking about the object. This problem is often described as the problem of saying under what conditions a person can be said to 'know who', or 'know which' object, it is that he has a belief about. The assumption is that triadic or de re belief implies that the believer knows who, or which object, his belief is about in the sense that he can in some salient sense identify or recognize it. Once the assumption is made that (2) implies that 'Ralph knows who the pertinent value of " $\mathrm{x}$ " is' (Quine, 1995, p. 97), the problem of interpreting such existentially quantified ascriptions becomes the problem of specifying when 'knowing who' conditions obtain. Since this is notoriously difficult, the problem of interpreting existentially quantified ascriptions becomes insoluble and Quine's later attitude that de re belief should be written off becomes understandable. But if what I have argued in Sect. 5 is correct-namely, that Quine's real problem with exportation is that his endorsement of its general validity is inconsistent with his doctrine of the opacity of de dicto belief because it requires de dicto belief to be relational and opacity prohibits this - then a solution is readily available.

\section{Loar's modification of Quine's intensional account}

Although it seems not to have been generally recognized, Loar (1972) has provided the solution: treat all relational states of mind as properly reported in the de re way (though Loar may not agree with this way of putting it). So (8), for example, should be replaced with the de re:

(10) Believes (Ralph, $x[x$ is Ortcutt and $x$ is a spy], Ortcutt),

as the proper representation of the relational state of mind reported in the ascription 'Ralph believes that Ortcutt is a spy'. But why the conjunctive intension ' $x[x$ is Ortcutt and $x$ is a spy]' rather than simply ' $x[x$ is a spy]'? Loar's ingenious and under-appreciated idea is that the first occurrence of 'Ortcutt' in the intension captures the fact that Ralph is, on this occasion, thinking about Ortcutt as Ortcutt, and thus accounts for the 'surface' substitution failure in the vernacular ascription. Earlier (in Sect. 3) I remarked on the crucial role that banning LTD-type conjunctions plays in Quine's account. Recall (from Sect. 4) that we are operating with a single sense of belief (the original belief ${ }_{1}$ ) that 'disallows' (LTD). It is this condition that tells us how Ralph is, on any given occasion, thinking of Ortcutt, and therefore which co-referring expressions are not substitutable in the intensional term. For example, if Ralph refuses to apply the conjunctive predicate being the man at the beach and a spy to Ortcutt, on some occasion, then we cannot, on that occasion, substitute 'the man at the beach' for 'Ortcutt' in the intensional term in (10). The second (extensional) occurrence of 'Ortcutt' is in referential position and thus captures the relational aspect of the ascription. In short, (10) captures both the substitution failure in 'Ralph believes that Ortcutt is a spy' and the fact that it nonetheless relates Ralph to Ortcutt. ${ }^{16}$ The conjunctive form can capture the now familiar 'dual role' of singular terms in belief reports. (10) in turn entails (6), by what Loar calls 'conjunction elimination' (CE):

(6) Believes (Ralph, $x[x$ is a spy], Ortcutt),

upon which we can then unproblematically existentially generalize, arriving at:

16 A similar proposal has been made by Burge (1977a).
Springer 
(7) $\exists y($ Believes (Ralph, $x[x$ is a spy], $y)$ ),

which is the symbolization of Quine's original example of the relational sense of believing someone to be a spy. The proposal, in brief, is that the relevant singular term in an ascription of a relational state of mind is already 'exported', for it is already in purely referential position. ${ }^{17}$

What then of de dicto, that is, dyadic belief? Is there such a thing? As Loar observes, 'Some belief reports do imply that the believer stands in certain relations to particular items ... . Other belief reports do not have such import, but seem to assert something of a rather more general nature about the believer, as well as about his beliefs' (1972, p. 58). Although Loar does not do so, it is plausible to identify de dicto beliefs with these 'more general' beliefs, which include the kinds of beliefs Quine originally dubbed 'notional' (in Forbes's sense of 'domain independent'); other examples are: 'Maggie believes democracy is the tyranny of the majority', 'Tom believes in justification by faith alone', 'Jack believes dualism is incoherent', etc. ${ }^{18}$ There are obviously millions more.

But are not those philosophers who maintain that there are de dicto beliefs with singular representational elements in their contents getting at a legitimate distinction, namely, between those attitude reports that make reference to the way the subject represents the object of his belief and those reports that do not? After all, it may be said, to think about something one must think about it in a particular way, one must represent it in some fashion, have some 'notion' of it. There is no such thing as 'bare reference' to an object. I agree that in order for a person to think about an object, he must think about the object in some particular way. But this 'truism', if such it be, is fully compatible with the claim that all relational belief is de re in Quine's multigrade sense. For the way in which a person thinks about the object of his thought can be represented as his having a certain conjunctive de re belief about the object in question, as Loar again points out (1972, pp. 52-53) - as in (10) above, where Ralph is said to think of Ortcutt as Ortcutt. Indeed, I would go beyond Loar and conjecture quite generally that:

(L) Believes $\left(S,\left\ulcorner\lambda\left[\Phi_{\lambda}\right]\right\urcorner, x\right) \leftrightarrow \exists \alpha\left(\right.$ Believes $\left(S,\left\ulcorner\lambda\left[\lambda=\alpha \& \Phi_{\lambda}\right]\right\urcorner, x\right)$,

where $\Phi$ is a predicative concept and $\alpha$ is an individual concept. ${ }^{19}$ The left-to-right direction captures the truism that in order for a subject to predicate a property of

17 In 'Demonstratives' (1989a), Kaplan says, 'indexical names must be exportable, not because of some special justification for the transformation from a de dicto occurrence to a de re occurrence, but because indexicals are devices of direct reference and have no de dicto occurrences. I am reminded of the Zen ko-an: How do you get the goose out of the bottle? Answers: It's out!' (p. 554n69). Following Loar, my suggestion here is effectively an extension of Kaplan's to all singular terms: what appear to be relational de dicto beliefs are really de re beliefs in which the singular terms are already 'out' in goose-like fashion. In 'Afterthoughts' (1989b, pp. 605-606) Kaplan renounces this view in part because of qualms surrounding the relation between de re belief and 'knowing who'. I try to dispel these qualms below in Sect. 8 .

18 Loar's example is: 'William believes that what goes up must come down'.

19 Here we have quantification over individual concepts - not something Quine is likely to approve of! As I said in note 9, my aim is not to defend Quine's system to the letter, only a modified form of his intensional account. (Quine's defense of the intensional account is later described by him in 'Intensions Revisited' (1977) as his being 'in the position of a Jewish chef preparing ham for a gentile clientele'. I consider myself a gentile client.). But why then describe the view as Quinean at all? My answer is that the view is Quinean relative to Kaplan's (1968-1969) proposal, because it operates with a single primitive sense of belief de re that is neither reducible to, nor definable in terms of, de dicto (propositional) belief and a strong epistemic notion of representation (cf. Wallace 1972). 
an object he must single out the object by some means - be it a definite description, proper name, indexical or demonstrative. If Ralph believes Ortcutt to be a spy, then there must be some individual concept $\alpha$ that Ralph uses to single out Ortcutt and which is such that Ralph believes Ortcutt to have the property of being both the extension of $\alpha$ and a spy. This is precisely what (10) does. The right-to-left direction of (L) embodies a special instance of (CE) where one of the properties in the conjunctive property is the property of being the extension of $\alpha$.

\section{Weakly epistemic and strongly epistemic relational states of mind}

At the beginning of Sect. VII of 'Quantifying In', Kaplan writes: 'further exploration with our version of Bel [i.e., triadic or de re belief] suggests that the rule of exportation fails to mesh with the intuitive ideas that originally led Quine to the introduction of Bel'. Does the above account not fall prey to Kaplan's complaint that the exported form of (6) conflicts with the 'intuitive idea' behind (7)? It would if the intuitive idea behind (7) were what Kaplan thinks it is, namely, that (7) expresses a fact that would interest the F.B.I.. If the reasoning in Sect. 6 is along the right lines, however, this is not the intuitive idea behind (7).

While it is certainly true that there is a 'vast difference' between (7) and (9), this difference is not one of 'knowing who' is a spy in contrast (merely) to believing in the existence of spies. The 'vital' relational/notional contrast, as originally presented by Quine in the opening pages of Q\&PA, is, I have argued, first and foremost that between states of mind that relate subjects to particular objects and those that do not, (though Quine himself seems not to have been entirely clear about this, as only four years later, in Word and Object (p. 148), we find him remarking on the 'urgent information the sentence "There is someone whom I believe to be a spy" imparts, in contrast to "I believe that someone is a spy" (in the weak sense of "I believe there are spies")'). But it is obvious that a relational state of mind per se need not be one in which the subject knows who his belief is about, and hence, it need not be of any interest to the F.B.I.. The 'knowing who'/'merely believing in the existence of' contrast is far from exhaustive. Consider the relational sense of hunting and wanting, which Q\&PA opens with:

(Q1) $(\exists x)(x$ is a lion \& Ernest is hunting $x)$

(Q2) $(\exists x)(x$ is a sloop \& I want $x){ }^{20}$

20 One issue raised by Q\&PA is how to symbolize the notional readings of ascriptions of what are sometimes called 'objectual' attitudes, which involve verbs that are sometimes called 'intensional transitives'. Whereas belief ascriptions take propositions as their complement clauses, ascriptions of wanting and hunting do not, at least not at the surface level: their complements tend to be noun phrases, as in Quine's 'I want a sloop' and 'Ernest is hunting lions', which have quantified noun phrases as their complements. Other 'intentional transitives' include 'seeking', 'looking for', 'worshipping', 'fearing', 'loving', 'hating', 'loathing'. The central problem with intensional transitives with quantified noun phrases is that since Russell's and Quine's distinctions of scope are not directly applicable (because of the lack of any 'inner sentential contexts', as Kaplan (1986, p. 266) puts it) it is hard to see how to draw the notional/relational contrast for these cases. Quine's way out of this is to rephrase notional readings of objectual ascriptions so that they do have an inner sentential context (e.g., 'I want it to be the case that I own a sloop' and 'Ernest strives to make it true that he himself finds a lion'). But it is very hard to believe that this 'propositionalizing' will work for all objectual attitude ascriptions that have notional readings. So we are left with the question of how to provide a logical form for 'non-propositionalizable' notional objectual ascriptions. See Forbes (2000) for a good discussion of this issue. 
The force of (Q1), Quine says, is that 'there is some individual lion (or several) which Ernest is hunting; stray circus property, for example' and (Q2) 'is suitable insofar as there may be said to be a certain sloop that I want' (p. 183). These are the relational readings of, respectively, 'Ernest is hunting lions' and 'I want a sloop', in contrast to their notional readings. Nothing in (Q1) and (Q2) indicates one way or the other whether Ernest knows which lions he is hunting, or that I know which sloop it is that I want, in some suitably strong epistemic sense according to which Ernest and I can be said to be acquainted or en rapport with those objects, or to be able to identify them, or recognize them in any interesting sense. It seems to me fully consistent with (Q1) and (Q2) that neither of us has ever been within a 100 miles of any lions or sloops and that neither of us has any very exact idea at all of which lions or sloops we want. Perhaps Ernest is a animal bounty hunter who has been hired by a circus to catch their escaped lions. Then (Q1) would capture Ernest's activity - his relational state of mind-for this activity would be one whose success depended on certain particular lions be captured. Not just any lions will do in such a case; on the contrary, the circus wants their specially trained lions back. Ernst too wants those lions (his payment depends on it) even though he may not yet know nearly enough about those lions to pique the interest of the dangerous fugitive animals section of the F.B.I.

Adapting some terminology from Dennett (1982) and Brandom (1994, chap. 8), let us call the states of mind underlying these relational readings of (Q1) and (Q2) weakly epistemic and the ones of interest to Kaplan and the 'knowing who' enthusiasts (and the F.B.I.), strongly epistemic. There can be no doubt that such weakly epistemic relational states of mind constitute a real and pervasive phenomenon. ${ }^{21}$ States of mind involving (non-empty) definite description concepts, for example, are just such phenomena, for they place the agent in a relation to some particular item via the mechanism of satisfaction or denotation (the aforementioned 'latitudinarian' sense of aboutness). In order for me to be in a relational state of mind-a state of mind whose content puts me into a relation with an element in the domain-I do not have to be in a strongly epistemic relational state of mind. The weakly epistemic reading of 'Ernest is hunting lions' is (Q1); the strongly epistemic reading will be something along the lines of:

(Q1S) $(\exists x)(x$ is a lion \& Ernest is hunting $x$ \& Ernest bears $R$ to $x)$,

in which ' $R$ ' is a mere place-holder for the relation between Ernest and the lion in question, whatever that may be, in virtue of which the former can be said to be in a strongly epistemic state of mind vis-à-vis the latter (e.g., being causally connected or 'being en rapport' or 'knowing who', in suitably technical senses). A report of a strongly epistemic state of mind always entails a report of a weakly epistemic state of mind, as (QS1) entails (Q1); though not vice-versa. (Q1S) might be true in a situation where Ernest has been mauled by a lion with distinctive markings and is seeking revenge (like Ahab in Moby Dick). Exactly how $R$ should be characterized is, of course, a matter of great controversy and various general accounts of it have been presented by Kaplan (1968-1969), Burge (1977a), Chisholm (1981) and Evans (1982), to name

21 Indeed, Kaplan (1989b) himself later admits that although 'acquisition of a name does not, in general, put us en rapport (in the language of "Quantifying In") with the referent ... this is not required for us to use the name in the standard way as a device of direct reference. Nor is it required for us to apprehend, to believe, to doubt, to assert, or to hold other de dicto attitudes toward the propositions we express using the name' (p. 605) Cf. Lycan (1985), who manages to find six different 'grades of aboutness' beginning with the purely denotational and ending with Russell's unmediated acquaintance with sense data. 
but a few. It may well be, however, that no such general account can be given simply because, as Quine says, 'The notion of knowing or believing who or what someone or something is, is utterly dependent on context. Sometimes, when we ask who someone is, we see the face and want the name; sometimes the reverse. Sometimes we want to know his role in the community. Of itself the notion is empty' $(1977$, p. 273; cf. Sosa, 1970). I cannot discuss this issue further here. But present purposes are anyway served by noting that there is a distinction between weakly epistemic and strongly epistemic states of mind (exhibited by, for example, the contrast between securing reference via a relation of denotation and securing it via some kind of vivid and memorable perceptual encounter), whether or not the latter is a uniform phenomenon, and that there is no compelling reason to impose a strong epistemic reading on (7) and its kin.

The conflation of the weakly epistemic and strongly epistemic categories of relational states of mind may have been abetted by Quine's choice of example to illustrate the relational/notional contrast as applied to the attitude of belief: namely, espionage. For the relational 'There is someone whom Ralph believes to be a spy' has tended to suggest to philosophers that Ralph knows who this person is in some critical sense. This strongly epistemic reading is often imposed by a subtle change from Quine's wording to 'There is someone whom Ralph suspects is a spy' and when suspicion and espionage are mixed together the strongly epistemic reading is all but irresistible and one starts thinking of the F.B.I. or C.I.A. It is not, however, the existential quantification that suggests the strongly epistemic reading but, I think, the topic of espionage. There is no reason to think that every time we affirm a relation of belief between a person and a particular object, we are committed to saying that that the person stands in a strongly epistemic relation to the object of his belief. Suppose Ralph believes that the man whom T.S. Eliot's poem 'Mr. Apollinax' is about is a propounder of logicism (because, say, he has overheard the tail end of a conversation in a college bar). So long as we believe that that poem is indeed about an actual person, we can report Ralph's belief by saying that he believes, of the man whom T.S. Eliot's poem 'Mr. Apollinax' is about, that he is a propounder of logicism; and if we have reason to think that the man whom T.S. Eliot's poem 'Mr. Apollinax' is about is Russell, we can report Ralph as believing, of Russell, that he is a propounder of logicism (cf. Sosa, 1970). Here we are saying that Ralph is belief-related (in the weak epistemic sense via the relation of denotation) to a certain man, on whom his belief's truth-value depends, and therefore that someone is believed by Ralph to be a propounder of logicism. This contrasts with the case where Ralph merely believes, notionally, that someone is a propounder of logicism, in the sense that propounders of logicism exist ('I'll bet someone has held this view', Ralph may conjecture after ruminating on the foundations of arithmetic). With this latter ascription, no relation between Ralph and any other person is affirmed; Ralph's state of mind is completely general in that it does not put Ralph into a relation with any object in the domain. Nothing in the former relational ascription need commit us to the claim that Ralph's belief puts him into some strong epistemic relation to Russell; that, for example, he knows who Russell is, is acquainted with him, can identify him, or anything of the sort. It is a further question whether an $R$-relation holds between Ralph and Russell. It may well be, of course, that certain psychological verbs in their de re modes (e.g., 'suspects') suggest or even imply strong epistemic readings (the presence of an $R$-relation). But not all, or even most, need do so. In short, I suggest that we need to sunder the issue of quantification from the issue of 'knowing who': the two have become unwarrantedly welded together, owing to the misinterpretation of notional as representational.

Springer 
Given the distinction between relational-as-domain-dependent and notional-asdomain-independent, it seems to me that the appeal of the strongly epistemic interpretation of existentially quantified de re belief reports is greatly diminished. In any case, the major problem facing any such view is simply that it is very hard to see how it can account for what are clearly weakly epistemic relational states of mind, states of mind that are domain dependent, rather than simply saying something entirely general, that is, domain independent. These states of mind cry out for symbolization with existential quantification; this was Quine's original starting point in Q\&PA. Yet they are not states of mind which are necessarily such that the subjects in them 'knows who' they are thinking of. How, then, are such graded 'intermediate' relational states of mind to symbolized by an approach that interprets existentially quantified and exported forms of attitude reports in a strongly epistemic manner?

\section{Thought and language connections: quotation and disquotation}

I want to turn now to the second problem facing Quine's view, the problem of suspended judgement with continued belief. My central claim will be that Quine's critics have not appreciated the crucial role that LTD (see Sect. 3 above) plays in Quine's view - but LTD is the key to seeing what the solution to the problem is. Recall again that Quine operates with a single sense of belief for which the rejection of LTD-type conjunctions is a condition (Sect. 4). The condition states that a person cannot believe $p$ while simultaneously sincerely denying the sentence $\ulcorner p\urcorner .22$ This is not, as it stands, entirely satisfactory, however. Quine seems to have overlooked two things: first, that a person may believe $p$ while simultaneously sincerely denying the sentence $\ulcorner p\urcorner$, if he does not understand what $\ulcorner p\urcorner$ says; second, that a person may fail to deny a sentence without thereby affirming it, for he can suspend judgement about it. Building in these factors, what should really be disallowed are conjunctions of the following type:

(LTD*) ( $w$ understands '.. ' and $w$ does not affirm ' ...') \& $w$ believes ....

In other words, what we want to rule out is a person's believing $p$ all the while either denying $\ulcorner p\urcorner$ or suspending judgement concerning $\ulcorner p\urcorner$ when he understands what $\ulcorner p\urcorner$ says. For one does not affirm a sentence (that one understands and has considered) if and only if one either denies the sentence or suspends judgement concerning it. Assuming that the act of affirming (or assenting) and denying (or rejecting) sentences is equivalent to believing those sentences to be true and false, respectively, as the case may be, the negation of (LTD*) amounts to:

$\neg[(S$ understands $\ulcorner p\urcorner \& \neg S$ believes $\ulcorner p\urcorner$ is true $) \& S$ believes $p]$,

which is equivalent to:

(QP) $S$ understands $\ulcorner p\urcorner \rightarrow(S$ believes $p \rightarrow S$ believes $\ulcorner p\urcorner$ is true $)$.

It is clear that Quine also accepts a principle according to which understandingly to affirm $\ulcorner p\urcorner$ 'counts as showing' that one believes $p$ (1960, p. 145); in other words:

(DP) $S$ understands $\ulcorner p\urcorner \rightarrow(S$ believes $\ulcorner p\urcorner$ is true $\rightarrow S$ believes $p)$.

(QP) and (DP) are, then, the two 'language-thought' principles presupposed by Quine in his discussions of psychological attitudes. Putting the conjunction of (DP) and (QP)

$22 ، p\urcorner$, should be read an referring to the sentence an ascriber uses to express the proposition $p$ in an ascription of belief that $p$. 
together we arrive at the key language-thought connection Quine assumes:

(LTC) $S$ understands $\ulcorner p\urcorner \rightarrow(S$ believes $p \leftrightarrow S$ believes $\ulcorner p\urcorner$ is true $)$.

(DP) and (QP) stand, respectively, for the 'Disquotation Principle' and the 'Quotation Principle' and (LTC) for 'Language-Thought Connection'. The first two names come from Kripke (1979) and Salmon (1986), respectively, though it is Kripke who first explicitly formulates the principles that take these names. His 'strengthened "biconditional" form of the disquotation principle' (Kripke, 1979) is a version of (LTC). ${ }^{23}$

As we have seen, Quine's central problem in Q\&PA is to provide distinct logical forms for ascriptions of quantified notional and relational attitudes. The first Russellian attempt to do so with 'permutations of components'-namely, attitude verbs and quantifiers - fails, for one half of it, the symbolization of the relational senses, involves quantifying into the position governed by the attitude verb; this is deemed incoherent by Quine because such positions resist substitutivity. That they resist substitutivity is demonstrated by the story of Ralph and Ortcutt and Quine's Fregean assumption (LTC) or, more specifically, that part of it embodied in (QP). The reason why substitution of 'the man at the beach' for 'the man in the brown hat' in 'Ralph believes that the man in the brown is a spy' is said to fail is the assumption that Ralph believes only those things reportable by sentences to which he would understandingly assent. Since he does not so assent to 'The man at the beach is a spy' he cannot believe that the man at the beach is a spy. The ascription 'Ralph believes that the man at the beach is a spy' is therefore false; substitution fails. Notice that without the assumption of (QP) there would be no problem of quantifying in for Quine to solve; for without (QP) substitution goes through and quantification in is therefore unproblematic. Now, consideration of whether (QP), or any of its cousins, is true is beyond the scope of this paper; my aim here is confined to marking out its essential role in Quine's argument against quantifying in and in his conception of belief. ${ }^{24}$

To continue, we know from Quine's story about Ralph that he believes sentence (a) is true and believes sentence (b) is false:

(a) The man in the brown hat is a spy

(b) The man at the beach is a spy.

By (DP) we can conclude that that (3) is true and by (QP) that (4) is true:

(3) Ralph believes that the man in the brown hat is a spy

(4) Ralph does not believe that the man seen at the beach is a spy,

which are to be represented triadically (see Sect. 7), substituting 'Ortcutt' throughout, as:

(11) Believes (Ralph, $x[x$ is the man in the brown hat and $x$ is a spy], Ortcutt)

(12) $\neg$ Believes (Ralph, $x\left[x\right.$ is the man at the beach and $x$ is a spy], Ortcutt). ${ }^{25}$

23 (LTC), or something very close it, is generally endorsed by Fregeans (cf. Evans 1982, p. 18f on the 'Intuitive Criterion of Difference'). The (QP) part of (LTC), however, is generally rejected by Russellians; see, e.g., Salmon (1986, Appendix A). These matters are discussed at greater length in my 2004b.

24 Again, for some discussion of this, see my 2004b.

25 Strictly speaking, in order to get (4) from (QP) we need to assume that if Ralph believes that the sentence 'The man at the beach is a spy' is false then he does not also believe that it is true-which seems a perfectly safe assumption in this context. The question whether the general principle, that if a person believes a sentence to be true then he does not also believe it to be false, is true, is not, of course, settled, and any discussion of this would need to take account of Kripke-style Paderewski cases.

iㅡㄹ Springer 
By (CE) from Sect. 7, (11) entails (6):

(6) Believes (Ralph, $x[x$ is a spy], Ortcutt).

Ralph also affirms the sentence:

(c) The man at the beach is not a spy,

as well as denying sentence (b), thereby demonstrating, by (DP), that

(13) Ralph believes that the man at the beach is not a spy

is true, as well as (4). (13) is represented as the triadic (14), with the substitution of 'Ortcutt' for 'the man at the beach':

(14) Believes (Ralph, $x$ [x is the man at the beach \& $x$ is not a spy], Ortcutt)

from which we can infer by (CE):

(15) Believes (Ralph, $x[x$ is a not spy], Ortcutt)

(16) Believes (Ralph, $x[x$ is the man at the beach], Ortcutt)

But, as Quine made clear, the 'near contraries' (6) and (15) do not entail:

Believes (Ralph, $x$ [ $x$ is a spy and $x$ is not spy], Ortcutt),

for while Ralph ascribes the properties of being a spy and not being a spy to Ortcutt, he does not ascribe the (impossible) property of being and not being a spy to Ortcutt or indeed to anyone. Bringing together the most important facts about Ralph's doxastic situation vis-à-vis Ortcutt, in terms of relational triadic belief, we have:

(6) Believes (Ralph, $x[x$ is a spy], Ortcutt)

(11) Believes (Ralph, $x[x$ is the man in the brown hat and $x$ is a spy], Ortcutt)

(12) $\neg$ Believes (Ralph, $x[x$ is the man at the beach and $x$ is a spy], Ortcutt)

(14) Believes (Ralph, $x[x$ is the man at the beach and $x$ is not a spy], Ortcutt)

(15) Believes (Ralph, $x[x$ is a not spy], Ortcutt)

(16) Believes (Ralph, $x[x$ is the man at the beach], Ortcutt).

These are Ralph's key de re beliefs about Ortcutt.

\section{The problem of suspended judgement with continued belief}

Suspension of judgement or belief de re is suspension of judgement with respect to whether a particular thing has a certain property and suspension of judgement de dicto is suspension of judgement about whether a certain proposition is true. In 'Quantifying In' Kaplan argues that Quine's account of belief is incapable of representing certain cases of suspension of judgement de re and that some kind of de dicto analysis or reduction is required to do so. The very phenomenon of de re suspension of judgement therefore lends support to the view that all belief is de dicto or at least that de dicto belief is more basic than de re in the sense that de re belief is really just a special case of de dicto. ${ }^{26}$ Indeed, this highly influential argument was part of a larger project of Kaplan's the aim of which was to give a Fregean analysis of de re belief in which it is analyzed as de dicto belief.

26 E.g., for Kaplan (1968-1969) a de re belief is a de dicto belief whose content contains a special mental representation; for Salmon (1998) a de re belief is a de dicto belief about a singular (or 'Russellian') proposition; and for Evans (1982) and McDowell (1984) a de re belief is a de dicto belief whose content contains a 'de re sense' that essentially involves its reference. 
Kaplan's Fregean analysis of (6) is:

(K6) $\exists \alpha(R(\alpha$, Ortcutt, Ralph) \& Believes (Ralph, $\ulcorner\alpha$ is a spy $\urcorner))$.

The first conjunct says that $\alpha$ 'represents' Ortcutt to Ralph and the second that Ralph believes the proposition or thought containing $\alpha$ as a constituent. Kaplan argues that his analysis is superior to Quine's because it can represent certain cases of suspended belief whereas Quine's cannot. To illustrate this, Kaplan continues Quine's story to a later time at which Ralph begins to suspect that the man at the beach may be a spy too, so that (15) becomes false. He does not, however, conclude that the man at the beach definitely is a spy; rather, he suspends judgement as to his spyhood. It seems that the following must now be true, substituting 'Ortcutt' for 'the man at the beach',

(17) $\neg$ Believes (Ralph, $x[x$ is not a spy], Ortcutt)

(18) $\neg$ Believes (Ralph, $x[x$ is a spy], Ortcutt).

At this later time, Ralph is to all appearances engaging in de re suspension of judgement with respect to Ortcutt; thereby neither believing of him that he is a spy nor believing of him that he is not a spy. The problem is immediately apparent: (18) contradicts the continued truth of (6); for (6) is still true on the basis of (11), that is, on the basis of Ralph's belief that the man in the brown hat is a spy. The problem, then, is to express what (18) is trying to express in the later part of the story consistently with (6). Quine needs to be able to represent this 'suspension of judgement with continued belief'. But this is just what Kaplan claims Quine cannot do.

From Kaplan's perspective, (18) is ambiguous between two different readings which can only be brought out on a de dicto analysis like his. On Kaplan's analysis, (18) could mean either:

(K18a) $\neg \exists \alpha\left(R\left(\alpha\right.\right.$, Ortcutt, Ralph) \& Believes (Ralph, $\left.\left.\ulcorner\alpha \text { is a spy }\urcorner^{\urcorner}\right)\right)$

or

(K18b) $\exists \alpha\left(R\left(\alpha\right.\right.$, Ortcutt, Ralph) \& $\neg$ Believes (Ralph, $\left\ulcorner\alpha\right.$ is a spy $\left.{ }^{\urcorner}\right)$).

Only (K18a) is inconsistent with (6). Once we distinguish (K18a) from (K18b), however, and read (18) as (K18b) the contradiction disappears and we are able to express suspended judgement. The full implications for belief of Ralph's suspension of judgement, in Kaplan's system, therefore come out as:

(KS) $\exists \alpha\left(R\left(\alpha\right.\right.$, Ortcutt, Ralph) \& $\neg B$ (Ralph, $\left\ulcorner\alpha\right.$ is a spy $\left.{ }^{\urcorner}\right) \& \neg B$ (Ralph, $\ulcorner\alpha$ is not a spy ?),

which is consistent with:

(K6) $\exists \alpha(R(\alpha$, Ortcutt, Ralph) \& $B($ Ralph, $\ulcorner\alpha$ is a spy $\urcorner))$,

so long as the $\alpha$ s are different (which they are, one being the man in the brown hat and the other the man at the beach). Since Quine's system cannot distinguish between $(\mathrm{K} 18 \mathrm{a})$ and $(\mathrm{K} 18 \mathrm{~b})$ he cannot express suspension of judgement de re. The upshot is that de re belief must be analysed as de dicto belief and that therefore de dicto belief is more basic than de re, in the sense that de re belief is really just a special case of $d e$ dicto belief. ${ }^{27}$

27 Kaplan's problem of suspended judgement with continued belief has been used by Russellians such as Salmon (1986, pp. 92-113) to argue for the necessity of a ternary analysis of de dicto belief as a relation among thinkers, propositions and modes of presentation of propositions. For discussion see my 2004a where I argue that no such analysis is necessary.

Springer 


\section{The way out}

It seems to me that this argument from suspended judgement in favour of de dicto reduction is unsound, however, because the modified Quinean account of de re belief is capable of expressing what happens in the later part of the story. That is, the Quinean account is able to provide a plausible replacement for the troublesome (18). As we shall see, it is (LTC) that tells us what this replacement is.

To see this, we need to consider the later phase of the story in somewhat more detail than Quine's critics are wont to do. In Kaplan's continuation of the story, as he describes it, 'Ralph's suspicions regarding even the man at the beach have begun to grow. Not that Ralph now proclaims that respected citizen to be a spy, but Ralph now suspends judgement as to the man's spyhood' (1968-69). Ralph has not changed his mind about whether the man in the brown hat is a spy: (11) and (6) are still true. Ralph has, however, changed his mind about whether the man at the beach is a spy: whereas he was formerly convinced that he was no spy he now no longer believes he is no spy. (LTC) comes crucially into play here. For Quine - and presumably Kaplan too, at least Kaplan in 1968-1969-this means that, at the very least, though he used to, Ralph no longer believes sentence (c) to be true:

(c) The man at the beach is not a spy.

Given (QP) this means that (14) is now false. Kaplan, of course, claims something stronger than this; he claims that (15) is false too, that is, that (17) is true. This is correct. For Ralph does not believe any other sentence that says that Ortcutt is not a spy, under some other designation of him, and so it follows that:

$\neg \exists \alpha$ [Believes (Ralph, $x[x=\alpha \& x$ is not a spy], Ortcutt)].

Given this, it follows from (L) (from Sect. 7) that (15) is false. Of course, this is only one half of Ralph's suspended judgement. The other half is exhibited by his still not believing that the sentence:

(b) The man at the beach is a spy

is true, in virtue of which (12) is still true. Here we reach the crux. For Kaplan seems to assume that not only is (12) intuitively true but that (18) is as well-and it is (18) that leads to the contradiction with (6). But this stronger assumption - that in Kaplan's continuation of the story (18) is intuitively true - is not, I think, justified, as I shall try to show.

In Ralph's situation in the later part of the story, when he is suspending judgement, (12) and (6) are both true. Unlike the case with (c), (14) and (15), we cannot infer, on the basis of Ralph's non-affirmation of (b), that (6) is false. Indeed, we have already agreed that (6) is still true, in virtue of the fact that Ralph still assents to sentence (a) 'The man in the brown hat is a spy'. Since he has not changed his mind about the truth of this sentence it follows from (DP) that (11) is still true and by (CE) that (6) is therefore still true. A conjunctive de re belief, such as 'Ralph believes Ortcutt to be the man at the beach and a spy', is only a sufficient condition, via (CE), for the corresponding non-conjunctive de re belief, 'Ralph believes Ortcutt to be a spy' - not a necessary one, so not having the conjunctive de re belief, by not believing the appropriate sentence to be true, does not entail not having the corresponding non-conjunctive de re belief. The subject may yet have another conjunctive de re belief that is also sufficient for the non-conjunctive de re belief in question-which is 
precisely what has happened to Ralph, for he affirms sentence (a) and thus (11) and (6) are true. In other words, because (11) is true, it is false that

$\neg \exists \alpha$ [Believes (Ralph, $x[x=\alpha \& x$ is a spy], Ortcutt)].

So we cannot use (L) to derive (18) (in the way that we used it to derive (17)). Kaplan's error, I am suggesting, lies in jumping to the conclusion that, given Quine's view of belief de re, (18) must be true in the later part of the story.

But, in fact, as Kaplan's own telling of the later phase indicates, the most that can be said is that (12) is true; as he says 'Ralph's suspicions regarding ... the man at the beach have begun to grow' (my emphasis). But (12) has been true all along; that is, even in the earlier part of the story, before Ralph begins to suspect the man at the beach, it is true that he fails to believe that the man at the beach is a spy. This is because he believes the man at the beach is not a spy. There are two ways to fail to believe something: one can disbelieve it or one can simply not believe it, either because one has never considered the matter or because one has considered the matter and decided to suspend judgement concerning it. Ralph has moved from disbelief regarding the spyhood of the man at the beach to suspension of judgement concerning his spyhood. But this in no way alters the fact that all along he has failed to believe the man at the beach to be a spy. The only change wrought by Ralph's new suspension of judgement is his new failure to disbelieve the man at the beach to be a spy. He always failed to believe he was a spy; he now also fails to believe he is not a spy. The doxastic element of Ralph's suspension of judgement de re amounts then to this:

(16) Believes (Ralph, $x[x$ is the man at the beach], Ortcutt)

(12) $\neg$ Believes (Ralph, $x[x$ is the man at the beach and $x$ is a spy], Ortcutt).

(19) $\neg$ Believes (Ralph, $x[x$ is the man at the beach and $x$ is not a spy], Ortcutt)

in which (12) takes the place of (18) and is, unlike (18), consistent with (6). ${ }^{28}$ (12) and (19) are true in virtue of the fact that he fails to believe either 'The man at the beach is a spy' or 'The man at the beach is not a spy' is true and (QP). ${ }^{29}$ (16), from Sect. 9, is a necessary doxastic component of Ralph's suspension of judgement, since it is consistent with (12) and (19) by themselves that Ralph have no beliefs at all, or indeed any other attitudes, about Ortcutt, because, say, he has never encountered him or heard about him. (16) plays the role in the modified Quinean account that Kaplan's representation clause in (KS) does in his de dicto-cum-representational account:

$R(\alpha$, Ortcutt, Ralph),

which ensures that the second, belief clause:

$\left(\neg B\right.$ (Ralph, $\left\ulcorner\alpha\right.$ is a spy $\left.{ }^{\urcorner}\right) \& \neg B\left(\right.$ Ralph, $\left\ulcorner\alpha\right.$ is not a spy $\left.{ }^{\urcorner}\right)$

is not trivially true. The Quinean account thus differs from Kaplan's proposal in that it does not appeal to a strongly epistemic notion of representation but expresses the

\footnotetext{
28 I emphasize that (12) replaces (18). It is not a representation of the vernacular 'Ortcutt is not believed by Ralph to be a spy', which is precisely what (18) is. Indeed, it could not be, for (18) is false and (12) is true.

29 (12), (16) and (19) are still insufficient to guarantee Ralph's suspension of judgement; they capture at most the doxastic part of suspended judgement, which is the only issue under consideration here. See Heidelberger (1974) and Devitt (1976).
} 
doxastic component of suspended judgement purely in terms of weakly epistemic belief $d e r e .^{30}$

The question naturally arises as to which is a more appropriate primitive, Quine's (weakly epistemic) concept of de re belief or Kaplan's (strongly epistemic) concept of de dicto-cum-representational belief. My own view is sympathetic to John Wallace, who finds 'Kaplan's primitives " $\alpha$ is a name of $x$ for Ralph" ... and " $\alpha$ is (sufficiently) vivid" not less obscure than the relational [i.e., de re] sense of belief' (1972, p. 92); but this large and difficult issue needs more discussion than I can offer here. ${ }^{31}$

To conclude, given the details of the elabourated Quinean conception of belief developed here, there are no grounds for claiming that (18) is true and Quine is not therefore forced into any contradiction. The false and misleading intuition that the vernacular ascription 'Ortcutt is not believed by Ralph to be a spy' is true in the later part of the story is captured and explained by (12). That (12) is the right representation is shown by the crucial role that (LTC) plays in defining Quine's primitive concept of de re belief. Kaplan's argument against Quine's analysis of belief de re thus collapses. A corollary of this is that one central argument for a de dicto reduction of de re belief likewise collapses.

Acknowledgements I am grateful to two anonymous referees of this journal for challenging criticisms and helpful suggestions that have led to significant improvements on the original manuscript.

\section{References}

Almog, J., Perry, J., \& Wettstein, H. (Eds.) (1989). Themes from Kaplan. Oxford: Oxford University Press.

Brandom, R. (1994). Making it explicit: Reasoning, representing, and discursive committment. Cambridge, MA: Harvard University Press.

Burge, T. (1977a). Belief De Re. Journal of Philosophy, 74, 338-362.

Burge, T. (1977b). Kaplan, Quine and suspended belief. Philosophical Studies 31, 197-203.

Chisholm, R. (1981). The first person. Minneapolis: University of Minnesota Press.

Crawford, S. (2004a). A solution for Russellians to a puzzle about belief. Analysis, 64, 223-229.

Crawford, S. (2004b). Pure Russellianism. Philosophical Papers, 33, 171-202.

Crimmins, M. (1995). Notional Specificity. Mind and Language, 10, 464-477.

Dennett, D. (1982). Beyond belief. Reprinted in Dennett, The intentional stance. Cambridge, MA: MIT Press, 1987.

Devitt, M. (1976). Suspension of judgment: a response to Heidelberger on Kaplan, Journal of Philosophical Logic, 5, 17-24.

Evans, G. (1982). The varieties of reference. Oxford: Clarendon Press.

Fine, K. (1989). The problem of de re modality. In J. Almog, J. Perry \& Wettstein (Eds.), Themes from Kaplan. Oxford: Oxford University Press.

30 Cf. Burge (1977b, p. 200) and see Salmon (1998, p. 97) for a good commentary on the issue between Kaplan's strongly epistemic representational account and Burge's counter-proposal on Quine's behalf. My diagnosis of the situation differs from both Burge and Salmon in assigning (LTC) a central role, which obviates the need to appeal, a la Burge, to irreducibly indexical modes of presentation (a strongly epistemic ' $R$ relation' in the terms of Sect. 8), or, a la Salmon, modes of presentation of propositions, in order to solve the problem.

31 Wallace (1972) considers three ways in which the issue of appropriate primitives might be settled in favour of Kaplan, all of which he finds wanting. He fails, however, to consider a potential fourth way: viz., that Kaplan's primitive allows for a system with greater expressive power than Quine's, because it enables suspension of judgement to be represented while Quine's does not. As I understand it, this is one of Kaplan's central arguments in favour of his primitive. If what I have argued is correct, this fourth way fails, because suspension of judgement can be represented using Quine's primitive. 
Fine, K. (1990). Quine on quantifying in. In C. A. Anderson, \& O. Joseph (Eds.), Propositional attitudes. the role of content in logic, language, and mind. Stanford: Center for the Study of Language and Information.

Forbes, G. (2000). Objectual attitudes. Linguistics and Philosophy, 23, 141-183.

Forbes, G. (1996). Substitutivity and the coherence of quantifying in. Philosophical Review, 105, $337-372$.

Heidelberger, H. (1974). Kaplan on Quine and suspension of judgment. Journal of Philosophical Logic, 3, 441-443.

Kaplan, D. (1968-1969). Quantifying in. Synthese 19, 178-214.

Kaplan, D. (1986). Opacity. In L. E. Hahn, \& A. S. Paul (Eds.), The Philosophy of W. V. Quine. La Salle, Illinois: Open Court.

Kaplan, D. (1989a). Demonstratives. In J. Almog, J. Perry, \& H. Wettstein (Eds.), Themes from Kaplan. Oxford: Oxford University Press.

Kaplan, D. (1989b). Afterthoughts. J. Almog, J. Perry, \& H. Wettstein (Eds.), Themes from Kaplan. Oxford: Oxford University Press.

Kripke, S. (1979). A puzzle about belief. In A. Margalit (Ed.), Meaning and use. Dordretch: Reidel.

Kripke, S. (2005). Russell's notion of scope. Mind, 114, 1005-1037.

Loar, B. (1972). Reference and propositional attitudes. Philosophical Review, 80, 43-62.

Lycan, W. (1985). Thoughts about things. In M. Brand, \& R. M. Harnish, (Eds.), The representation of knowledge and belief. Tucson: University of Arizona Press.

McDowell, J. (1984). De Re senses. Philosophical Quarterly, 34, 283-294.

Quine, W. V. (1956). Quantifiers and propositional attitudes. Reprinted in The ways of paradox and other essays. New York: Random House (1966).

Quine, W. V. (1960). Word and object. Cambridge, MA: MIT Press.

Quine, W. V. (1968). Reply to Kaplan. Synthese 19, 311-315.

Quine, W. V. (1977). Intensions revisited. In P. A. French, T. E. Uehling, Jr., \& H. K. Wettstein. (Eds.), Contemporary perspectives in the philosophy of language. Minneapolis: University of Minnesota Press.

Quine, W. V. (1986a). Reply to David Kaplan. In L.E. Hahn, \& A.S, Paul (Eds.), The philosophy of W. V. Quine. La Salle, Illinois: Open Court.

Quine, W. V. (1986b). Philosophy of logic (2nd ed.). Cambridge, MA: Harvard University Press.

Quine, W. V. (1995). From stimulus to science. Cambridge, MA: Harvard University Press.

Recanati, F. (2000). Relational belief reports. Philosophical Studies, 100, 255-272.

Richard, M. (2001). Seeking a centaur, adoring adonis: intensional transitives and empty terms. Midwest Studies in Philosophy, 25, 103-127.

Richard, M. (1990). Propositional attitudes. Cambridge: Cambridge University Press.

Russell, B. (1910). On the nature of truth and falsehood. Philosophical essays. London: George Allen and Unwin.

Salmon, N. (1986). Frege's puzzle. Cambridge, MA: MIT Press.

Salmon N. (1995). Relational belief. In L. Paolo, \& S. Marco (Eds.), On Quine: New essays. Cambridge: Cambridge University Press.

Salmon N. (1998). Is De Re belief reducible to De Dicto? Canadian Journal of Philosophy, Supplementary Volume 23, 85-109.

Sosa, E. (1970). Propositional attitudes De Dicto and De Re. Journal of Philosophy, 67, 883-896.

Stalnaker, R. (1998). Content and context. Oxford: Clarendon Press.

Stich, S. (1983). From folk psychology to cognitive science. Cambridge, MA: MIT Press.

Wallace, J. (1972). Belief and satisfaction. Nous, 6, 85-95. 